\title{
Fast Degradation of Azo Dyes by Using Cu-based Metallic Glasses
}

\author{
Xiao Chen $\mathrm{Xu}^{1,2}$, Ke Qiang Qiu ${ }^{1, *}$ \\ ${ }^{1}$ Material Science and Engineering College, Shenyang University of Technology, Shenyang, China \\ ${ }^{2}$ Mechanical and Power Engineering College, Yingkou Institute of Technology, Yingkou, China
}

Email address:

kqqiu@163.com (Ke Qiang Qiu)

*Corresponding author

To cite this article:

Xiao Chen Xu, Ke Qiang Qiu. Fast Degradation of Azo Dyes by Using Cu-based Metallic Glasses. Advances in Materials. Vol. 10, No. 1, 2021, pp. 1-4. doi: 10.11648/j.am.20211001.11

Received: January 11, 2021; Accepted: January 20, 2021; Published: January 28, 2021

\begin{abstract}
Wastewater containing azo dye has become a main harm in water pollution. Therefore, development of environment friendly materials with efficient purifying capacity seized more and more attention of people devoting to dye wastewater processing. On the other hand, advancement of metallic glasses in degrading organic water contaminant has also received wide concern. Cu-based amorphous alloy has excellent corrosion resistance and good stability in the process of degradation of azo dyes In the present thesis, single roller melt-spinning method $\mathrm{Cu}-\mathrm{Zr}-\mathrm{Al}-\mathrm{Y}$ metallic glasses is applied so as to investigate degradation of azo dye Direct Blue in acid and alkaline solution. It is concluded that when the value of it is $2,25 \mu \mathrm{m} \sim 30 \mu \mathrm{m}$ thick stripes of non-crystalline structures will be formed. With variation of the $\mathrm{pH}$, rate of degradation will also change. The degradation rate in acidic solution is higher than that in alkaline and neutral solution. This is due to the fact that Azo bond and $\mathrm{Cu}$-based amorphous alloy in dye molecule requires quite low activation energy to react, which makes degradation easier to proceed and thus macroscopic decoloration is also quickened. After the treatment of wastewater, white corrosion products will be produced on the surface of amorphous strip. It will affect the degradation effect.
\end{abstract}

Keywords: Cu-based Metallic Glasses, Direct Blue Azo Dye, Degradation

\section{Introduction}

In the last few years, the discharge of industrial wastewater, especially printing and dyeing wastewater, has caused great harm to the natural environment and people's living water, so treatment of wastewater has become urgent. At present, there are many methods to degrade dye wastewater, such as, Activated carbon adsorption method, chemical oxidation method, and biodegradation method. However, it is necessary to find a method that is efficient, cost-effective and environmental friendly to solve the problem, from the standpoints of both resource conservation and environmental remediation. Therefore, besides its application value in mechanics, magnetic property, decay resistance etc, non-crystalline material is also known as a functional material, and can be used as catalyzer [1, 2], biological material [3, 4], Soft magnetic material $[5,6]$ and in magneto caloric effect [7, 8]. It is recently discovered that, $\mathrm{Fe}-\mathrm{Si}-\mathrm{B}$ amorphous alloy could degrade the azo dye of acid orange II dye solution $[9$, 10], and degrading effect of it is better than homo-componential crystalline alloy and commercial iron powder Wang [11] produced $\mathrm{Mg}-\mathrm{Zn}-\mathrm{Ca}$ powder through ball-milling method, and it turns out that $\mathrm{Mg}-\mathrm{Zn}-\mathrm{Ca}$ powder bears stronger degrading and decay resistance properties than its corresponding crystalline-state powder. Amorphous-state $\mathrm{Mg}-\mathrm{Zn}$-Ca powder also shows a superior reacting efficiency in degrading the Congo Red dye [12].

We studied the reactivity of $\mathrm{Cu}-\mathrm{Zr}-\mathrm{Al}-\mathrm{Y}$ metallic glasses in degrading Direct Blue azo dye solutions. The influence of $\mathrm{pH}$, reaction temperature, and dosage has been studied. The reaction mechanism has been studied based on the evolution of surface morphologies and the compositions change for the metallic glass ribbons. 


\section{Experimental}

\subsection{Reactivity Measurements}

All experiments were conducted in $100 \mathrm{~mL}$ beakers, which were placed in a magnetic stirrer. During the reaction, the solution was rod-stirred at a xed speed. At present time intervals $3 \mathrm{~mL}$ aliquots were removed with a syringe and altered with $0.45 \mathrm{~mm}$ membranes [13]. The altered samples were pipetted out and subjected to UV-vis spectrum scanning. The reacted amorphous alloy strips were recycled and used for the degradation of dye wastewater again to test the reusability of amorphous alloy in the degradation of dye wastewater. The mass of amorphous alloy strips used in each experiment was 1.0 $\mathrm{g}$, the volume of was $30 \mathrm{~mL}$, the initial concentration of Direct Blue solution was $0.1 \mathrm{~g} / \mathrm{L}$, and the solution temperature was kept at $40^{\circ} \mathrm{C}$ in the degradation experiment, and the experimental parameters remained unchanged unless specified. The acidity of the solutions was tuned by adding $1 \mathrm{M}$ HCL solution or $1 \mathrm{M} \mathrm{NaOH}$ solution. For each time, $30 \mathrm{~mL}$ Direct Dlue solution was put into the $100 \mathrm{~mL}$ beaker for reaction test. The temperature was controlled by magnetic stirrer.

\subsection{Fabrication and Characterization}

The alloy ingots with nominal compositions of $\mathrm{Cu}_{46} \mathrm{Zr}_{45} \mathrm{Al}_{7} \mathrm{Y}_{2}$ were prepared by induction melting the mix-tures of pure $\mathrm{Cu}, \mathrm{Zr}$, Al, Ymetals under high purity argon atmosphere. The $\mathrm{Cu}_{46} \mathrm{Zr}_{45} \mathrm{Al}_{7} \mathrm{Y}_{2}$ metallic glass ribbons were fabricated by single roller melt-spinning method under the protection of argon atmosphere [14]. The atomic structure of the ribbons was verifified by X-ray diffraction.

\subsection{Mechanism Analysis}

The morphology and structure of the ribbons before and after degradation were examined by scanning electron microscopy (SEM) and XRD. The surface compositions of ribbons was also examined by energy dispersive spectroscopy (EDS) equipped on the SEM machine. [14] UV-vis spectra of azo dye solutions were recorded using an UV-vis spectrometer.

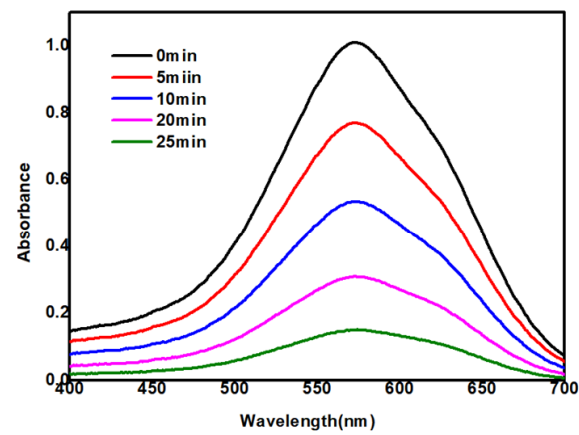

(a)

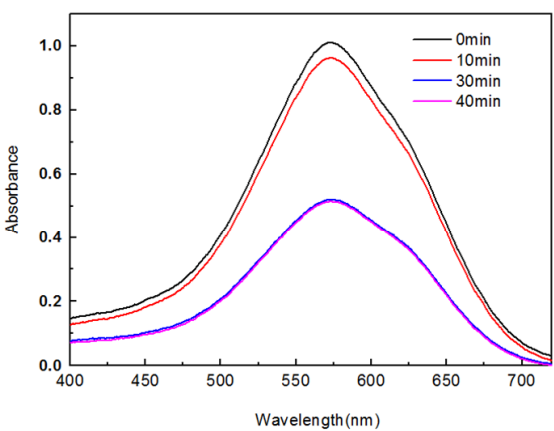

(b)

\section{Results and Discussion}

\subsection{Characterization of the $\mathrm{Cu}_{46} \mathrm{Zr}_{45} \mathrm{Al}_{7} \mathrm{Y}_{2}$ Catalyst}

Figure 1 shows the XRD patterns of $\mathrm{Cu}_{46} \mathrm{Zr}_{45} \mathrm{Al}_{7} \mathrm{Y}_{2}$ metallic glass ribbonss. It can be seen from the figure that the alloy strip is completely amorphous, and there are two obvious diffuse reflection peaks at the interval of $30-50^{\circ}$ and $60-75^{\circ}$, which is the typical structure of amorphous alloy.

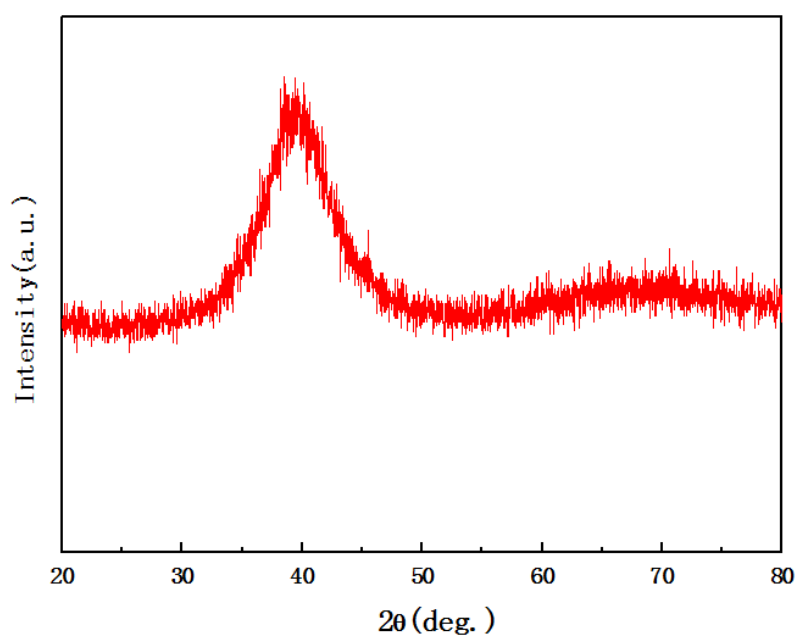

Figure 1. XRD patterns of $\mathrm{Cu}_{46} \mathrm{Zr}_{45} \mathrm{Al}_{7} \mathrm{Y}_{2}$ amorphous ribbons.

\subsection{The Reactivity in Solutions with Different pH}

Figure 2 shows the effect of $\mathrm{pH}$ value on degradation efficiency from azo dyes by using $\mathrm{Cu}$-Based amorphous alloys. The $\mathrm{pH}$ of the solution plays an important role in the degradation of the dye. A slight change in $\mathrm{pH}$ will alter the degradation of the dye by the material. For most dye wastewater, the $\mathrm{pH}$ is in the range of $2-10$. In this work, therefore, we chose to degrade the Direct Blue at $\mathrm{pH}=2,7$ and 10. Figure 2(a) shows the UV absorption spectra of Direct Blue 6 dye by using $\mathrm{Cu}_{46} \mathrm{Zr}_{45} \mathrm{Al}_{7} \mathrm{Y}_{2}$ amorphous ribbons. It can indicate that the dye is completely degraded. The characteristic absorption peak of Direct Dlue dye molecules arises from $573 \mathrm{~nm}$.

Figure 2. UV-visible absorption spectrum of the Drect Blue solution of the $\mathrm{Cu}_{6} \mathrm{Zr}_{45} \mathrm{Al} \mathrm{l}_{7} \mathrm{Y}_{2}$ amorphous alloy strip at (a) $\mathrm{pH}=2$, (b) $\mathrm{pH}=7 \mathrm{and}$, (c) $\mathrm{pH}=10$ trested at different treating time

In acidic conditions, the UV-visible absorption spectrum of the Drect Blue 6 solution of the $\mathrm{Cu}_{46} \mathrm{Zr}_{45} \mathrm{Al}_{7} \mathrm{Y}_{2}$ amorphous alloy strip degradation is shown in Figure 2 (a). It can be seen that under acidic conditions, as the reaction time prolongs, the intensity of the absorption peak at $573 \mathrm{~nm}$ decreases continuously, indicating that the $-\mathrm{N}=\mathrm{N}$ - structure of the direct 
blue dye molecule is continuously destroyed until it is almost completely decomposed. In acidic conditions, the Direct Dlue dye can be completely degraded in $25 \mathrm{~min}$ with high degradation efficiency. At $\mathrm{pH}=7$, the $\mathrm{UV}$-visible absorption spectrum of the Direct Dlue solution of the $\mathrm{Cu}_{46} \mathrm{Zr}_{45} \mathrm{Al}_{7} \mathrm{Y}_{2}$ amorphous alloy strip degradation is shown in Figure 2(b). For every 10 minutes increase, the intensity of the absorption peak at $573 \mathrm{~nm}$ is less and less, which indicates that the degradation rate of Direct Dlue is slower and slower, especially when the reaction proceeds to $40 \mathrm{~min}$, the change in absorption peak intensity has been very weak at $573 \mathrm{~nm}$. Figure 2(c) shows that in alkaline conditions, the Direct Dlue degradation of becomes more difficult. This is because the Direct Blue solution is negatively charged in the acidic solution, so when the $\mathrm{p} \mathrm{H}$ is low, it is easily adsorbed on the

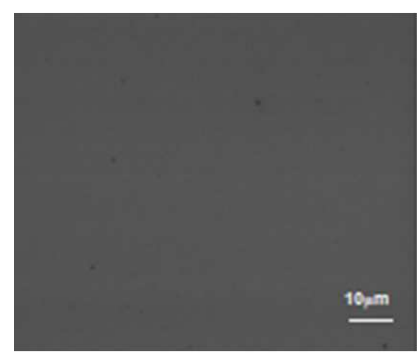

(a)

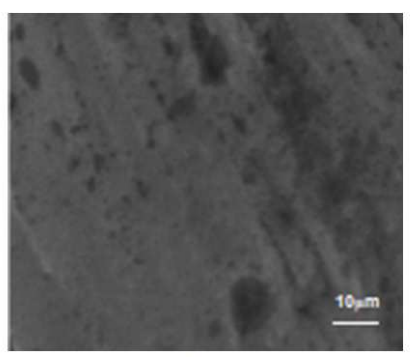

(b)

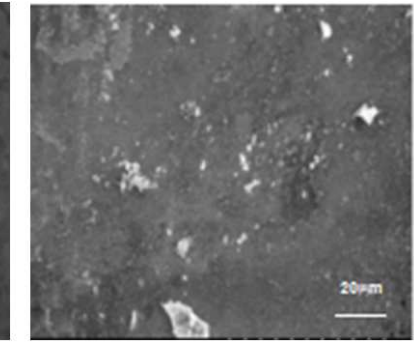

(c) surface of the positively charged cu-based amorphous alloy, and as the $\mathrm{pH}$ of the solution increases, the positive charge is reduced, the adsorption becomes more and more difficult, and the rate of subsequent degradation reaction is further slowed down.

\subsection{The Analysis of Surface Morphology}

In order to clarity the surface morphology of glassy ribbon after cycle use on the degradation efficiency of simulated images of glassy ribbons before degradation. As shown in Figure 3(a) the surface of the amorphous strip is smooth without cracks before degradation. Figure (b), (c) and (d) show that there are white corrosion products on the surface of amorphous alloy after wastewater degradation [15].

Figure 3. SEM images of $\mathrm{Cu}_{46} \mathrm{Zr}_{45} \mathrm{Al}_{7} \mathrm{Y}_{2}$ glassy ribbon before degradation (a) and after the first cycle (b) and two cycles (c) and five cycles of use (d).

So far, many researchers have used different amorphous alloys to treat various kinds of wastewater. As shown in Table 1 , the comparison of research results shows that $\mathrm{Cu}$-based amorphous alloy has outstanding advantages.

Table 1. Comparison of azo dyes treated with different amorphous alloys.

\begin{tabular}{llll}
\hline Pollutants & Material & Time & References \\
\hline Direct blue2B & Al-Ni-Y & $120 \mathrm{~min}$ & {$[14]$} \\
Direct blue6 & Fe-Si-B & $60 \mathrm{~min}$ & {$[13]$} \\
Direct blue6 & Fe-B & $60 \mathrm{~min}$ & {$[16]$} \\
Direct blue6 & Cu-Zr-Al-Y & $25 \mathrm{~min}$ & Tihis work \\
\hline
\end{tabular}

\section{Conclusions}

$\mathrm{Cu}$-based amorphous alloy has excellent corrosion resistance, so it has less corrosion loss in the process of degradation of azo dyes and can maintain its own stability.

1) The optimal processing parameters are included the $\mathrm{pH}$ value of 2 , under the optimal parameters, the removal rates can reach up to $98 \%$ respectively. This is because the Direct Blue solution is negatively charged in the acidic solution, so when the $\mathrm{p} \mathrm{H}$ is low, it is easily adsorbed on the surface of the positively charged cu-based amorphous alloy, and as the $\mathrm{pH}$ of the solution increases, the positive charge is reduced, the adsorption becomes more and more difficult

2) $\mathrm{Cu}_{46} \mathrm{Zr}_{45} \mathrm{Al}_{7} \mathrm{Y}_{2}$ glassy ribbon possesses a good structural stability and excellent surface activity.

\section{Acknowledgements}

This work was supported by Natural Science Foundation of
Liaoning Province (Grant No. 2019ZD0373).

\section{References}

[1] Carmo M, Sekol R. C, Ding S. Y. Bulk metallic glass nanowire architecture for electrochemical applications [J]. ACS Nano, 2011, 5: 2979-2983.

[2] Tang $\mathrm{Y}$, Chen $\mathrm{N}$, et al. Insight into the high reactivity of commercial $\mathrm{Fe}-\mathrm{Si}$-B amorphous zero-valent iron in degrading azo dye solutions [J]. RSC Adv, 2015, 34032-34039.

[3] Zberg B, Uggowitzer P J et al. Mg-Zn-Ca glasses without clinically observable hydrogen evolution for biodegradable implants [J]. Nat Mater, 2009, 887-891.

[4] Schroers J, Kumar G et al. Bulk metallic glasses for biomedical applications [J]. JOM, 2009, 61: 21-29.

[5] Egami T. Magnetic amorphous alloys: physical and technological applications [J]. Rep Prog Phys, 1984, 47: 1601-1725.

[6] Zhang M X, Kong F L, et al. Soft magnetic properties of bulk Fe-C-Mo-P-C-B-Si glassy core prepared by copper mold casting [J]. Appl Phys, 2012, 111 (07): 312.

[7] Wang W H, Bulk metallic glasses with functional physical properties [J]. Adv Mater. 2009, 21: 4524-4544.

[8] Huo J T, Huo L S et al. The magnetocaloric effect of Gd-Tb-Dy-Al-M (M Fe, Co and Ni) highentropy bulk metallic glasses [J]. Intermetallics, 2015, 58: 31-35.

[9] Zhang] C. Q., Zhang H. F., et al, Decolorization of azo dye solution by Fe-Mo-Si-B amorphous alloy [J]. J. Non Cryst. Solids, 2010, 356: 1703-1706. 
[10] Zhang C. Q, Zhu Z. W, et al. Rapid reductive degradation of azo dyes by a unique structure of amorphous alloys [J]. Chin. Sci. Bull, 2011, 56: 3988-3992.

[11] Wang J Q, Liu Y H, Chen M W, et al. Excellent capability in degrading azo dyes by $\mathrm{Mg} \mathrm{Zn}$-based metallic glass powders [J]. Sci Rep, 2012.

[12] M. Ramya, M. Karthika, R. Selvakumar. A facile and efficient single step ball milling process for synthesis of partially amorphous $\mathrm{Mg}-\mathrm{Zn}-\mathrm{Ca}$ alloy powders for dye degradation [J]. Alloys Compd. [J]. 2017, 696: 185-192.

[13] Tang Y., Shao Y., et al. Insight into the high reactivity of commercial $\mathrm{Fe}-\mathrm{Si}-\mathrm{B}$ amorphous zero-valent iron in degrading azo dye solutions [J]. RSC Advances, 2015.

[14] Wang P P, Wang J Q, et al. Fast decolorization of azo dyes in both alkaline and acidic solutions by Al-based metallic glasses [J]. Journal of Alloys and Compounds, 2017, 701: 759-767.

[15] Xu X C, Shi Z L, et al. Electro-fenton degradation of simulated petroleum wastewater by using $\mathrm{Fe}_{78} \mathrm{Si}_{9} \mathrm{~B}_{13}$ metallicglasses [J]. Materials Research Express, 2020.

[16] Tang Y., Shao Y, et alRapid decomposition of Direct Blue 6 in neutral solution by Fe-B amorphous alloys. RSC Advs [J]. 2015, 5: 6215-6221. 